\title{
Workplace Bullying and Intention to Leave: The Moderating Effect of the Organizational Commitment
}

\author{
*Faheem Rasool, Farah Arzu, Ali Hasan, Arslan Rafi, Abdul Rauf Kashif \\ Iqra University, Islamabad, Pakistan \\ *hifaheem@gmail.com
}

\begin{abstract}
The main reasoning of this study is to figure out the relations among workplace bullying and turnover intention of the employee treating organization commitment as a moderating variable. Workplace bullying have a positive impact on intention to leave which reveals the widespread impact that bullying can have on targets in that still less rigorous types of bullying are coupled with victims intention to leave the workplace (e.g. department), the organization or the job. Workplace bullying are more relevant to systematic flaws in the organization and less to employees' performances while person-related bullying is related more to the personal characteristics of the victims, so irrespective of their commitment, exit from the organization in such circumstances happens to be the preferable alternative for the victim. This study provides an insight that the harmful effects of workplace bullying could be handled effectively through the moderating effects of organizational commitment on the relation between workplace bullying and intention to leave. It therefore, required conducting a further study on the join effects of organizational commitment and bullying in terms of some other variables such as in-role job performance, which are vital to the working of the organizations.
\end{abstract}

Keywords: Workforce bulling, Employees intention to leave, Diversity, Organizational Commitment

\section{Introduction}

Workplace bullying is becoming a core issue for the organizations now days. Employers and management scholars are paying lot of attention towards effective dealing of bullying. Bullying reduce the organizational performance by effecting the employee performance through both absenteeism and employee turnover from the organization (Hoel et al., 2003; Quine, 1999). In literature, turnover intention is found to be the most immediate and stronger antecedent of turnover (Mobley et al., 1979; Bluedom, 1982; Horner, Mobley \& Hollingworth, 1978; Steel \& Ovalle, 1984,). Therefore, in order to reduce the turnover intentions, it is highly important to specify and deal effectively with the turnover intentions. Commitment with Organization is one of the strongest antecedents of turnover intentions and turnover (Tumwesigye, 2010). In order to study the organizational behavior, organizational commitment plays a very important part. Organizational commitment is very much associated with the emotional, attitudinal, and cognitive constructs e.g. job satisfaction, employee behaviors and performance efficiencies, employee's work demands are e.g. responsibility and personal characteristics of the employee such as job tenure and age (Bateman \& Strasser, 1984). It is found that if employee's level of commitment is low to their organization, resultantly there is a high turnover intention and actual turnover rate of the employees (Allen \&Meyer, 1996). There is ample evidence in research history which reveals (Quine, 2001) that the relation among workplace bullying and employee turnover intention is moderated by some highly significant variables like Perceived Organizational Support (POS), but the most infusing variable that can change the relations among bullying and turnover intentions is organizational commitment, which is a gap that needs to be studied. The main reasoning of this study is to figure out the relations among workplace bullying and turnover intention of the employee treating organization commitment as a moderating variable. The purpose of this study is to figure out the relations among workplace bullying and turnover intention of the employee treating organization commitment as a moderating variable. The rationale of the study that the harmful effects of workplace bullying could be handled effectively through the moderating effects of organizational commitment on the relation between workplace bullying and intention to leave. It is therefore, required conducting a further study on the join effects of organizational commitment and bullying in terms of some other variables such as in-role job performance, which are vital to the working of the organizations. 


\section{Literature Review}

Workplace bullying affects a substantial part of the global workforce. During 1980s, an occupationalassociated psychological trouble was spotted; the degree of its existence was earlier not recognized. This sort of work-related disturbance was termed as "mobbing". Though the phenomenon of mobbing happens to be very old, still until early 1980 s it was not been addressed and analytically researched. Distressing, psychologically horrifying others or ganging up on someone are the most common negative practices associated with mobbing (Leymann, 1996). In 1992, the term "workplace bullying" was introduced for defining this kind of negative practices at workplace by Andrea Adams a British journalist (Namie, 2003). Namie and Gary in1998 used this term "workplace bullying" in U.S.A. in the popular press. Bullying has been defined by different researchers in different ways. Heinz Leymann is considered as the pioneer of the bullying research and according to him bullying reflects a depressing behavior that manifests itself in a negative upshot, primarily of a psychosomatic nature (Leymann, 1996). As these negative attitudes are caused due to some unethical practices in the workplace and they are found to be unwanted by the victims (Raknes \& Einarsen, 1997). According to several other authors, when an employee has an encounter with such kind of violent and unconstructive behaviors mainly of psychological nature, he happens to be a victim of workplace bullying, having disastrous effects on the targets such as exploitation, isolation, humiliation or intimidation (Leymann, 1996). So, instead of the nature of these unwanted negative behaviors, it has been emphasized that the persistency of experiencing this behavior i.e., the frequency and duration is the central characteristic of the conception of (Einarsen et al., 2003). Hence, instead of disconnected and isolated actions, the significant factors of bullying are increasing unsympathetic workplace interactions coupled with duration (over a period of time), patterning (of a diversity of behaviors involved) and reappearance (regularity) (Einarsen et al., 2003). Bullying is exercised through both indirect and direct actions: indirect acts of aggression include social segregation, gossiping and rumors while direct actions are public humiliation verbal abuse and accusations (Seigne, O’Moore, Smith \& McGuire, 1998).

Workplace bullying also results in creating harmful psychological effects on the victims (Stallworth \& Fox, 2005) including low self-esteem, depression, and suicidal thoughts (Matthiesen \& Einarsen, 1999). Research proves that victim of workplace bullying also suffered with some physiological ailments such as musculoskeletal pains, stomach disorders (Vartia 2001; 0'Moore et al., 1998) as well as cardiovascular diseases (Kivimaki et al., 2003).Another important factor that constitutes bullying is the difference of power among the groups involved in bullying (Niedl, 1996). This is the reason why the victim of bullying is reluctant to defend themselves or retard their ability to escape from the whole situation. Power is identified through certain factors such as access to the social support, knowledge, information, and experience (Einarsen et al., 2003). With the increase in the frequency and duration of experiencing bullying, the existing resources of the targets become exhausted and the victims feel more powerless (Leymann,1996).As far as workplace setting is concerned, bullying is classified into two distinct behaviors i.e., work-related behaviors and person-related behaviors. Insinuation about the intellectual capabilities of the victims and their social isolation are the few examples of person related bullying, whilst assigning an employee too many, too few or too easy tasks, or diligently criticizing the employee or his work, are some of the examples of work-related bullying (Einarsen, 1999). Even though bullying is mostly concerned with negative practices having disastrous psychological effects on the victim, there is ample evidence according to which the victims reported that they not only got the threats for violence but they are actually confronted with violence (Leymann, 1990).

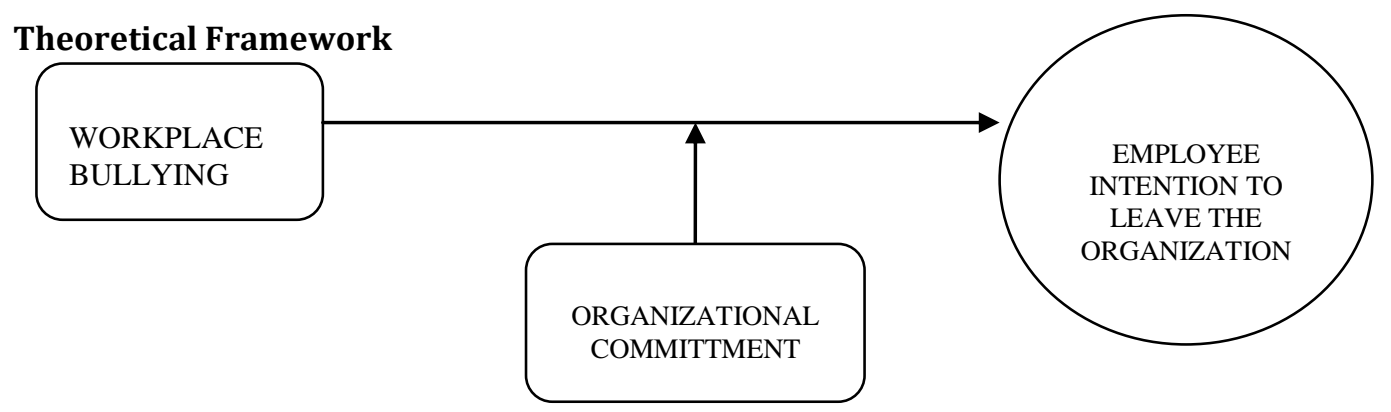


As far as the organizational performance is concerned, workplace bullying also impose harmful effects on the organizations as it disturbs not only the targeted person and all so to the witnesses (Hoel et al., 1999). This low efficiency of the employees ultimately reduces the efficiency of an organization in terms of innovation and outcome Rayner et al., 2002). Another major consequence of workplace bullying is that it negatively affects the level of job satisfaction and commitment of the employees with their organization (Cooper \& Hoel, 2000), which leads towards a greater ratio of absenteeism (Vartia, 2001) and enhance their intentions to switch over from the organization (Djurkovic et al., 2004). The strongest precursor of leaving the organization is found to be intention to leave (Begley, 1998), due to which an organization bears an extensive cost (Waldman et al., 2004; Cascio, 1987). According to a UK-based research, due to experiencing the bullying behavior, one quarter of the victims left their organizations (Cooper \& Rayner, 1997). Multiple definitions of organizational commitment are found in the literature. Commitment is a multi-dimensional model (Allen \& Meyer, 1991; 1993; 1997; Morrow, 1993 \& Etzioni, 1961). Organizational commitment is a multi-faceted phenomenon, primarily associated with emotional bonding of the employee with the organization, eagerness to some additional work for the organization, the extent of objective and value congruency with the organization, and aspiration to associate with the organization (Strasser \& Bateman, 1984). Also, organizational commitment is an adherent, affective affection to the goals values and goals of an organization, to one's role relative to the goals and values of an organization, separately from its entirely instrumental significance (Reyes, 2001). According to the three dimensional model given by Meyer and Allen there are three kinds of organizational commitment are identified that are: continuance commitment, normative, affective. Affective commitment it deals with the employee's emotional bonding and his involvement with the organization. Normative commitment refers to the commitment which is developed in an employee due to organizational obligations which forces an employee to retain in an organization. The third most imperative component of organizational commitment is continuance commitment. Continuance commitment is related to the commitment which makes an employee realize that he has to bear the cost of leaving that organization (Allen \& Meyer, 1991). Literature reveals that these three dimensions of organizational commitment represent a mental state that truly reflect the works association with organization or somehow they have the capability to effect the works decision to retain in the organization (Smith, Allen \& Meyer, 1993).

Because of its involvement with extra-role behaviors, organizational commitment has gained a lot of attention from researchers (Niehoff, Organ, \& Moorman, 1993), having its major impacts on absenteeism and turnover (Gellatly, 1995; Somers, 1993). Highly committed individuals are found to be suffered less with negative outcomes related to mental and physical ill-health, job satisfaction, and intention to leave the organization against those who have low level of committed (Czajka \& Begley, 1993). Career opportunities, work-life policies and job characteristics are found to be the significant determinants of organizational commitment (Ramay \& Bashir, 2008).Organizational commitment creates very constructive effects on the performance of an organization. For instance, employee regularity is the most positively related outcome to organizational commitment (Somers, 1995; Gellatlly, 1995; Steers, 1997). According to a research done on the group of insurance workers it was revealed that highly committed employees had lower levels of absenteeism and turnover (Boal \& Blau, 1987). Qualitative evidence reveals that the effective dealing by the organizations regarding the negative behaviors and emotional abuse being experienced by the victims, strongly moderates the relationships among workplace bullying and its harmful effects on the victims (Keashley, 2001). Various forms of negative workplace practices are strongly influenced by the way employees are committed to their organizations (Keashley, 2001). In addition, the formulation and implementation of various policies which are associated with the workplace bullying as well as several kinds of organizational support provided to the employee makes the employee to be more committed to the organization which helps them to deal with and respond effectively to the abuse at workplace (Keashley, 2001). Furthermore, there are few aspects of normative commitment that are linked somehow with the relational exchanges of social exchange theory for this reason organizational commitment strengthens the belief of an employee that the organization is really concerned by the employees' work-related distinctions, well-being, goals and values that creates a sense of obligation among the employees. The exchange of material and non-material rewards (economic exchanges and/or social exchanges) between actors is the fundamental principal of social exchange theory. Economicrelated exchanges are found to be temporary and short-term while social-related exchanges, due to the relational acquaintance between the parties involved induces deeper levels of trust. A sense of mutual obligation comes out as a result of social exchange (Blau, 1964, Tetrick \& Shore, 1991).So in this context, organizational commitment is also considered as one of the dimensions of social exchange prevalent $b / w$ the 
workers and organization because it is the commitment that inducts the feelings in the employees that organization values them and also committed to them (Eisenberg et al., 1986) which results in highly favorable outcomes for employee and for the organization. This paper proposed that the relations $\mathrm{b} / \mathrm{w}$ workplace bullying and intention to leave is moderated by the organizational commitment. Hypothesis of this is:

H1: The relationship between workplace bullying and intention to leave will be moderated by the organizational commitment.

\section{Discussion}

Workplace bullying have a positive impact on intention to leave which reveals the widespread impact that bullying can have on targets in that still less rigorous types of bullying are coupled with victims intention to leave the workplace (e.g. department), the organization or the job (Hoelet al., 2003).Organizational Commitment is a sort of social exchange $b / w$ workers and their organizations, due to which the workers things, depending on the manner their organizations value them, that the organization give due importance to their assistance and look after their interests (Tumwesigye, 2010). The social exchanges lead towards the growth of trustworthiness, faith and unnamed obligations (normative commitment), from the employees side on the part of the employees, to remain with the organization, based on the reciprocity norm. On the basis of these arguments, it says to the rationale that Organizational Commitment diminishes the intention to leave the workplace (Einarsen et al., 2003). Organizational commitment, hence, moderates the relation between workplace bullying and intention of the employees to leave the job (Stallworth \& Fox, 2005).It is reasonable that organizational commitment is essential in the existence of work that is related to bullying, because these sort of bullying deeds are directly related to the performance of the work of the victims in terms of reminders of mistakes and errors, criticisms and monitoring of work (Djurkovic et al., 2004). Besides, workplace bullying are more relevant to systematic flaws in the organization and less to employees' performances while person-related bullying is related more to the personal characteristics of the victims, so irrespective of their commitment, exit from the organization in such circumstances happens to be the preferable alternative for the victim (Ramay \& Bashir, 2008).

Future Recommendations: There is only one dependent variable in this study i.e. intention to leave is studied which is the limitation of this study. It therefore, required conducting a further study on the join effects of organizational commitment and bullying in terms of some other variables such as in-role job performance, which are vital to the working of the organizations. Moreover, we take only one moderator was in this study, and it would be useful to look at the possible effects of some other moderators, like personal characteristics of victims, on the association $b / w$ bullying and its different outcomes. In addition to this, no distinction was made in the present study between vertical and horizontal bullying. So, the moderating effect of organizational commitment on the relation $b / w$ workplace bullying and intention to leave could also be studied in this context.

\section{Managerial Implications}

This study provides an insight that the harmful effects of workplace bullying could be handled effectively through the moderating effects of organizational commitment on the relation between workplace bullying and intention to leave. The findings from this study possibly have widespread generalizations as the variables under consideration are not exceptional. The findings point out that the formulation and implementation of various policies which are associated with the workplace bullying as well as several kinds of organizational support provided to the employee makes the employee to show more loyalty with organization which helps them to deal with and respond effectively to the abuse at workplace (Keashley, 2001). It is quite necessary that when these negative acts are being reported by the victims, management need to take some positive steps that make obvious to the victims and the witnesses of these bullying behaviors. This attitude reveals to the employees that their organization supports them and values them (Hoel \& Salin, 2003; O'Moore et al., 1998) due to which employees feel more committed to their organization and the turnover intentions could be lessened. But for that, organizations need to formulate prescribed policies that clearly address that bullying is highly offensive and could hold serious cost for those who are practicing these negative behaviors. 
Such prime interventions are quite helpful in making a workplace free of all kind of bullying behaviors that resultantly reduce the employee as well as organizational performance. There are different ways through which organizations can express that in any case they support their employees' e.g. initiating employee support programs which facilitate the victims in such a way that they openly express their work-related or personal problems and assuring them that their organization will assist them, respond sensitively to their complaints and will safeguard their basic human rights. This will make the victims realize that their organization is highly anxious about their welfare which will increase the emotional bonding of the workers with their organization. Further, there is a need to enhance organization-wide interactions with an objective of keeping the employees' well-informed about the fact that organization will not tolerate the ill-treatment of its employees. This strategy to deal with workplace bullying very effective as it leads to the perception among the worker that the organization care them and things about their well-being.

\section{References}

Allen, N. J. \& Meyer, J. P. (1993). Organizational Commitment: Evidence of career stage effects? J. Bus. Res, 26(1), 49-61.

Allen, N. J. \& Meyer, J. P. (1996). Affective, continuance and normative commitment to the organization: an examination of construct validity. Journal of vocational behavior, 49, 252-276.and Emotional Abuse in the Workplace: International Perspectives in Research and Practice, London: Taylor \& Francis.

Bateman, T. S. \& Strasser, S. (1984). A longitudinal analysis of the antecedents of organizational commitment. Academy of Management Journal, 27, 95-112.

Bannister, B. D. \& Griffeth, R. W. (1986). Applying a causal analytic framework to the Mobley, Horner, and Hollingsworth (1978) turnover model: A useful reexamination. Journal of Management, 12, 433-443.

Begley, T. M. \& Czajka, J. M. (1993). Panel analysis of the moderating effects of commitment on job satisfaction, intent to quit and health following organizational change. Journal of Applied Psychology, $78,552-556$.

Begley, T. (1998). Coping strategies as predictors of employee distress and turnover after an organizational consolidation: A longitudinal analysis. Journal of Occupational and Organizational Psychology, 71, 305329.

Blau, G. \& Boal, K. (1987). Conceptualizing how job involvement and organizational commitment affect turnover and absenteeism. Academy of Management Review, 12(2), 288-300.

Blau, P. (1964). Exchange and Power in Social Life, New York: Wiley.

Bluedorn, A. C. (1982). A unified model of turnover from organizations. Human Relations, 35, 135-53.

Cascio, W. (1987). Costing Human Resources: The Financial Impact of Behavior in Organizations, Boston, MA: PWS-Kent.

Daniel, B. J. \& Harold, S. (1995). Automatically determining bilingual vocabulary from noisy bilingual corpora using variable bag estimation. International conference: Recent Advances in Natural Language Processing (TzigovChark, Bulgaria), 81-86.

Djurkovic, N., McCormack, D. \& Casimir, G. (2004). The physical and psychological effects of workplace bullying on intention to leave: a test of the psychosomatic and disability hypotheses. International Journal of Organization Theory and Behavior, 7, 469-497.

Einarsen, S. \& Matthiesen, S. (1999). Symptoms of post-traumatic stress among victims of bullying at work. Abstracts for the XIVth European Congress on Work and Organizational Psychology.

Einarsen, S. \& Raknes, B. (1997). Harassment at work and the victimization of men. Violence and Victims, 12, 247-263.

Einarsen, S. (1999).The nature and causes of bullying at work. International Journal of Manpower, 20(1/2), 16-27.

Einarsen, S., Hoel, H., Zapf, D. \& Cooper, C. (2003). The concept of bullying at work: the European tradition, in S. Einarsen, H. Hoel, D. Zapf and C. Cooper, Bullying and Emotional Abuse in the Workplace: International Perspectives in Research and Practice, London: Taylor and Francis.

Eisenberger, R., Huntington, R., Hutchison, S. \& Sowa, D. (1986). Perceived organizational support. Journal of Applied Psychology, 71, 500-507.

Etzioni, A. (1961). A comparative analysis of complex organizations. New York: Free Press.

Fox, S. \& Stallworth, L. (2005). Racial/ethnic bullying: exploring links between bullying and racism in the US 
workplace. Journal of Vocational Behavior, 66, 438-456.

Gellatly, I. R. (1995). Individual and group determinants of employee absenteeism: Test of a causal model. Journal of Organizational Behavior, 16, 469-486.

Hoel, H. \& Cooper, C. (2000). Destructive conflict and bullying at work. Unpublished report, University of Manchester Institute of Science and Technology, UK.

Hoel, H. \& Salin, D. (2003). Organizational antecedents of workplace bullying', in S. Einarsen, H. Hoel, D. Zapf and C. Cooper, Bullying and Emotional Abuse in the Workplace: International Perspectives in Research and Practice, London: Taylor and Francis.

Keashly, L. (2001). Interpersonal and systemic aspects of emotional abuse at work: the target's perspective. Violence and Victims, 16, 233-268.

Shahzad, K., Bashir, S., Ramay, I. M. (2008) Impact of HR Practices on Perceived Performance of University Teachers in Pakistan. International Review of Business Research Papers, 4(2), 302-315

Kivimaki, M., Virtanen, M., Vartia, M., Elovainio, M., Vahtera, J. \& Keltikangas-Jarvinen, L. (2003). Workplace bullying and the risk of cardiovascular disease and depression. Occupational and Environmental Medicine, 60, 779-783.

Leymann, H. (1990). Mobbing and psychological terror at workplaces. Violence and Victims, 5, 119-126.

Meyer, J. \& Allen, N. (1991). A three-component conceptualization of organizational commitment. Human Resource Manage. Rev., 1, 61-89.

Meyer, J. P. \& Allen, N. J. (1997). Commitment in the workplace: theory, research, and application. Thousand Oaks, CA: sage.

Moorman, R. H., Niehoff, B. P. \& Organ, D. W. (1993). Treating employees fairly and organizational citizenship behavior: Sorting the effects of job satisfaction, organizational commitment, and procedural justice._Employee Responsibilities and Rights Journal, 6, 209-225.

Mobley, W. H., Griffith, H. \& Megline, B. (1979). Review and conceptual analysis of the employee turnover process. Psychol. Bull, 86, 493-522.

Mobley, W. H., Horner, S. O. \& Hollingsworth, A. T. (1978).An evaluation of precursors of hospital employee turnover process. J. Appl. Psychol., 63, 408-14.

Morrow, P. (1993).The theory and measurement of work commitment. Greenwich, CT: JAI Press.

Namie, G. (2003a). The WBI 2003 report on abusive workplaces. Retrieved 10/ 19/03, 2003, from www.bullyinginstitute.organization.

Niedl, K. (1996). Mobbing and Well Being: Economic, Personal and Development Implications. European Journal of Work and Organizational Psychology, 5(2), 239-249.

O'Moore, M., Seigne, E., McGuire, L. \& Smith, M. (1998). Victims of workplace bullying in Ireland. The Irish Journal of Psychology, 19, 345-357.

Quine, L. (1999). Workplace bullying in NHS community trust: staff questionnaire survey. British Medical Journal, 318, 228-232.

Quine, L. (2001). Workplace bullying in nurses. Journal of Health Psychology, 6, 73-84.

Rayner, C. \& Cooper, C. (1997). Workplace bullying: myth or reality - can we afford to ignore it? Leadership and Organization Development Journal, 18, 211-214.

Reyes, P. (2001). Individual work orientations and teacher outcomes. Journal of Educational Research, 83(6), 327-335.

Shore, L. \& Tetrick, L. (1991). A construct validity study of the survey of perceived organizational support. Journal of Applied Psychology, 76, 637-643.

Steers, R. M. (1997). Antecedents and outcomes of organizational commitment. Administrative Science Quarterly, 17, 340-350.

Steel, R. P. \& Ovalle, N. K. (1984). A review and meta-analysis of research on the relationship between behavioral intentions and employee turnover. J. Appl. Psychol., 69(4), 673-686.

Vartia, M. (2001). Consequences of workplace bullying with respect to the well-being of its targets and the observers of bullying. Scandinavian Journal of Work Environment and Health, 27, 63-69.

Waldman, J. D., Kelly, F., Arora, S. \& Smith, H. L. (2004). The shocking cost of turnover in health care. Health Care Management Review, 29, 2-7. 